\title{
6
}

\section{Responding to Land Use Pressures: A State and Territory Perspective}

Richard W. Hicks

\section{Key Points}

- Under the Australian Constitution, each state and territory has responsibility for land use policy, planning and management.

- Each state has varying legislative drivers and land use pressures that present a range of challenges, including:

- biodiversity legislative reforms, which impact on planning controls of land use changes by restricting land use intensification, particularly as it relates to native vegetation management

- controlling the expansion of urban areas into intensive high-value agricultural lands

- mitigating the impacts of mining developments on surrounding land uses and rehabilitating mined areas to provide functioning ecosystems that can support viable land uses

- protecting waterways to ensure clean water supply and sustainability of the aquatic and marine environments. 
- Over the past 16 years, the state jurisdictions and relevant Australian government agencies have worked together to develop a comprehensive and consistent land use framework under the auspices of the Australian Collaborative Land Use and Management Program (ACLUMP).

- A consistent national framework for land use classification and mapping has strengthened the states' commitment to preparing state-wide land use information, resulting in the first national compilation of catchment-scale land use data in 2008.

- Most states are remapping or upgrading the precision of their original mapping to reflect this national framework. Under this national collaborative framework, all jurisdictions now share land use information, enabling a national report on land use change and trends to be prepared.

- Emerging trends arising from advances in technology, especially in remote sensing and computing technologies, are enabling improved monitoring and reporting of land use changes and trends.

The information presented in this chapter is largely based on information compiled from agency representatives involved in ACLUMP. ACLUMP is a partnership between Australian, state and territory government land management agencies, as well as relevant research organisations. This program promotes the development of nationally consistent land use and land management practices information for Australia.

\section{Responding to Land Use Pressures}

Under the Australian Constitution, the states and territories have responsibility for land use and management across a range of public and private land tenures. Changes to land use policy and planning can have a major bearing on the natural resource condition of land, water, air, soil and native vegetation. Changes in resource condition often have a long lag time-years or decades can pass before the ecological effects of changes in land management regimes and practices are observed (Thackway \& Freudenberger, 2016). Public-private responses to issues of declining resource condition are many and varied. They include targeted policy and planning responses to issues of salinity, poor water quality and the maintenance of biodiversity (e.g. Murray-Darling Basin planning and numerous land care strategies implemented by Australian and state 
governments over the past 30 years). This involves investigation of land use, land cover and land management, and developing trade-offs between competing use options and land management regimes (Lesslie, Barson \& Randall, 2008).

Before the 1980s, information that enabled the development of land use policy and planning instruments was generally derived from land system and soil maps (e.g. Department of Agriculture, 1985; Weston, Harbison, Leslie, Rosenthal \& Mayer, 1981). Since then, public agencies have produced maps of land use types and their extent by combining several data types: land use patterns derived from remotely sensed imagery, biophysical information, social and economic information, and groundbased surveys (e.g. Department of Conservation and Land Management, 1992; Department of Water Resources, 1989). These land use related datasets are employed by local, state and Australian government agencies to identify opportunities for appropriate intensification of land uses and improvements to land management regimes and practices. Evaluations of the outcomes of changing land use in combination with better management approaches have led to widespread and significant declines in dryland salinity and associated problems, decreased rates of wind and water erosion, and improved protection and management of native vegetation.

\section{Development of ACLUMP}

Before 1999, the availability of detailed mapping of land use in Australia was limited and uncoordinated across the various jurisdictions. Australian and state government agencies independently produced land use mapping at a range of scales using a variety of cartographic methods and classification systems.

ACLUMP was established in 2000 in response to increasingly complicated and complex land use policy and planning issues facing all Australian land management jurisdictions, including food security, vegetation and carbon management, biosecurity, climate change, sustainable agriculture and water management. At the same time, Australia started systematic reporting in respect to forest cover and national carbon accounting as a result of the Kyoto and United Nations reporting requirements. Each of these issues called for coordinated and cooperative approaches 
to developing a responsive national land use infrastructure. Key elements of the infrastructure included mapping, coordination and standards, communication and dissemination, and analysis and reporting. These elements are described in more detail below.

ACLUMP is overseen by a national committee representing Australian and state government agencies. The program promotes the development and use of a nationally consistent set of land use and land management practices and reporting codes throughout Australia. The principles of classification, decision rules for mapping and classification evolutions are continuously updated - the current version is 8.0 (Australian Bureau of Agricultural and Resource Economics and Sciences [ABARES], 2016).

In 1999, the National Land and Water Resources Audit, Department of Agriculture, Fisheries and Forestry (DAFF), Bureau of Rural Sciences (BRS), Murray-Darling Basin Commission and state agency partners commenced a collaborative national land use mapping initiative that led to the development of ACLUMP. DAFF accepted leadership for the national coordination of land use information in 2000, and BRS, later ABARES, took on responsibility for the development of ACLUMP. Mapping products are now in strong demand for a range of land management purposes, and there is widespread adoption of agreed standards. The importance of ACLUMP and the information it provides is widely recognised. For example, a recent report to the Australian Farm Institute (Budge et al., 2012) recommended that ACLUMP be strengthened and further supported.

ACLUMP's partners are well advanced in meeting catchment-scale (nominally $1: 50,000$ or 1:25,000 in intensively used areas) land use mapping goals. These are:

1. Comprehensiveness: continental mapping coverage at the catchment scale (excluding parts of the ACT) was completed in 2008. Since then, most jurisdictions have remapped areas. The last release of catchmentscale data compiled for Australia was in March 2015 (see Figure 6.1).

2. Accuracy: with some limited exceptions, all land use products have an overall (or total) accuracy of greater than 80 per cent. For jurisdictions that do not directly map using the Australian Land Use and Management (ALUM) classification (e.g. NSW and VIC), conversion tables have been developed to ensure that land use can be mapped consistently across Australia. 
3. Currency: ACLUMP partners have determined priorities for updating land use mapping. The mapping for many of the intensive agricultural areas is greater than five years old, while those for pastoral areas in Queensland and Western Australia are greater than 10 years old (see Figure 6.2). ACLUMP partners are addressing data currency through their respective state-based programs in accordance with the priorities identified, and in response to key policy drivers in each jurisdiction.

4. Scale: one of the major strengths of catchment-scale land use mapping is the high resolution at which it is produced. Most intensive agricultural areas are mapped at either 1:25,000 or 1:50,000, with a minimum mapping area of 2 hectares.

The primary challenges for land use mapping are maintaining accuracy and currency. However, given improvements in satellite imagery, especially the frequency of updates, as well as access to platforms such as Google Earth, these challenges can easily be addressed, as discussed below. The major focus is on measures that enable the use of ancillary data and land use change assessments, which contribute to improved accuracy and currency of catchment land use.

ACLUMP is well placed to strategically respond to land use and management challenges as they arise; this is due to the coordinated national network of state partners involved in the program. Recent increases in the extent of irrigated agriculture, vineyards and cereal cropping in some regions have raised the need for improved monitoring and reporting of land use changes and trends. A perennial problem for local and regional policy and planning are the land use issues associated with peri-urban and coastal areas, whereby land uses can change rapidly in response to the pressures of urbanisation (Lesslie et al., 2008).

Several states and territories are facing pressures of declining water availability, loss of soil carbon associated with broadscale agriculture and loss of biodiversity. Intensification of land uses is leading to demands from users for finer-scale and more current land use datasets. Map sheets for regions undergoing substantial change need to be updated regularly; this is increasingly being addressed by incorporating changes detected via remote sensing, or other spatially explicit data, into the existing land use datasets, and updating the metadata and validating the new land use map. 
The regular updating of data and information enables states to monitor and report changes and trends in land use; most states have undertaken to update their initial mapping, either via a second round of mapping or by using recent imagery.

Predictive modelling of natural resource management issues at the catchment level requires information about land management regimes and practices. In 2004, agreement was reached among relevant government departments, industry groups and scientific organisations on the need to develop a national categorisation and information system for land management practices (ACLUMP, 2010a, 2010b); however, the Land Use Management Information System (LUMIS) has not been fully developed or realised. Instead, in 2010 (or 2011), ACLUMP shifted its focus to improving its understanding of (and consistency in) the monitoring of ground cover changes across Australian landscapes. This shift was driven by the availability of new remote-sensing datasets that measured and reported ground cover changes and trends at a range of spatial and temporal scales. Recognition of the general decline in land condition across the continent due to ground cover management practices-particularly with respect to soil health, wind and water erosion, but also the effects on agricultural productivity—was another factor.

Having established a national ground cover monitoring program, ACLUMP has recently refocused its efforts to updating and improving land use mapping, particularly in those regions that are long outdated or have experienced significant or rapid land use change. While these developments are welcome, it remains difficult to distinguish local variations in ground cover that are due to management inputs from those that are due to rainfall extent and timing. It is also difficult to remotely identify various land management practices and the rapid changes occurring in cropping practice, due to the ongoing development of precision agricultural systems. This demonstrates the need for further calibration and validation of ground-cover mapping products. 


\section{Benefits of Adopting and Implementing the ACLUMP Program}

\section{National Benefits}

ACLUMP's overarching goal is to develop a forum to support an integrated land use and land management practices information system for Australia. Implementation of the nationally agreed ACLUMP approach has produced many benefits for the states and territories, such as:

- mapping: nationally consistent land use mapping for Australia at both national and catchment scales

- coordination and standards: agreed technical standards, including ALUM and LUMIS

- communication and dissemination: a national land use data directory and the maintenance of land use datasets on Australian and state government data repositories

- analysis and reporting: regional and national reporting of land use and land management practices, including change reporting and integrated assessments.

At the state level, land use information is collected to ACLUMP standards using the ALUM classification. This allows consistent reporting at the catchment scale, as well as at state, territory and national levels. Land use mapping technology and display at the desktop level may vary between jurisdictions; however, they all meet the agreed minimum standards collaboratively developed by ACLUMP's partners (Lesslie, Mewett \& Walcott, 2011; Mewett et al., 2013).

The land use information derived by the various state programs is used to support urban and regional planning, biodiversity regulations, bushfire planning and biosecurity planning, among other uses (see Figure 6.1) (OEH [Office of Environment and Heritage], 2016d). Other state and territory responsibilities include food security, vegetation and carbon management, biosecurity, climate change adaptation, sustainable agriculture and water management. 
LAND USE IN AUSTRALIA

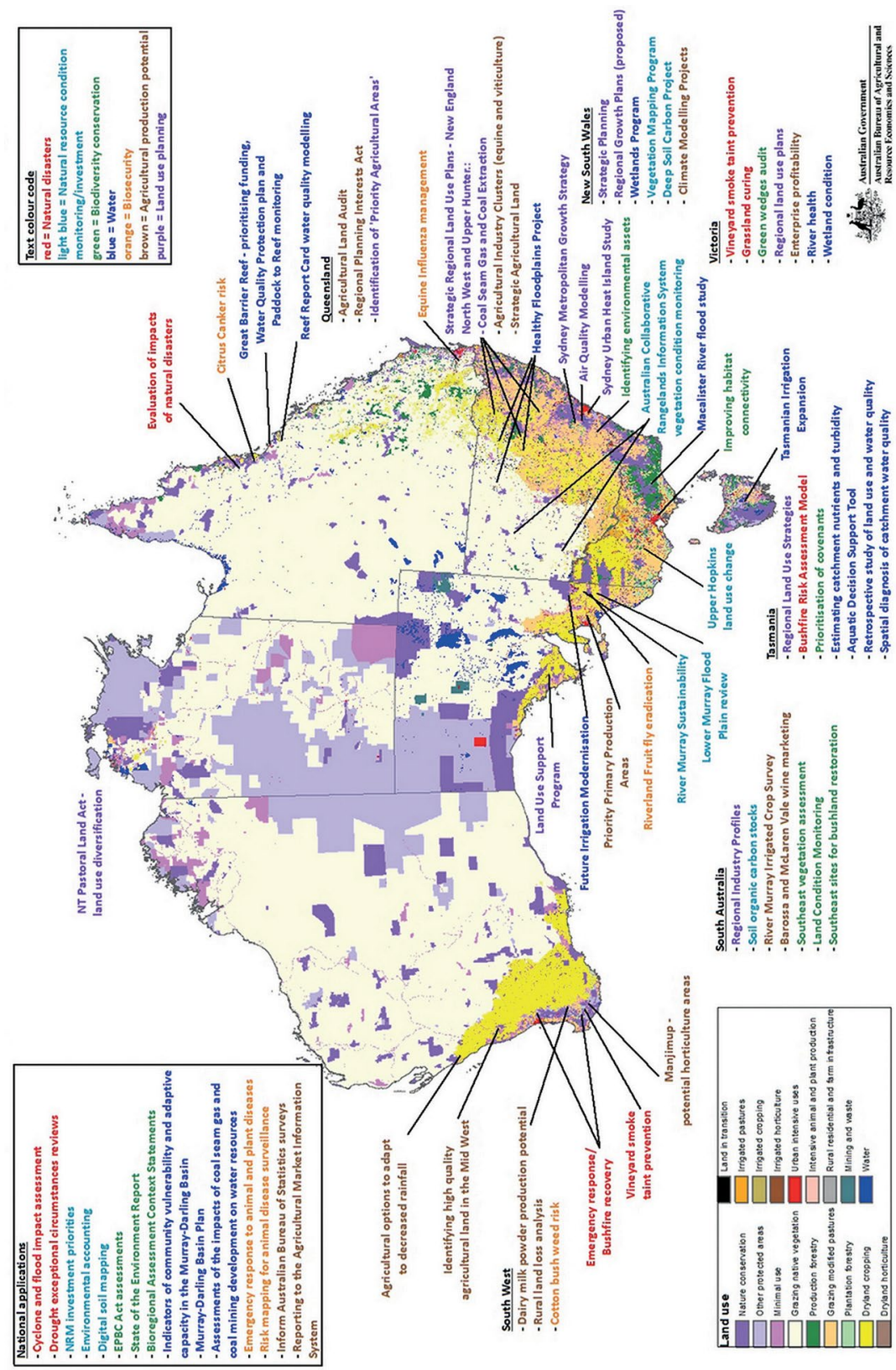

Figure 6.1: Applications of catchment-scale land use data.

Source: ABARES (2015, Figure 1). 
In regard to collecting, monitoring and employing data and information relevant to land use policy and planning, some states rely on intensive manual interpretation of aerial and satellite imagery — such as MODIS (Moderate Resolution Imaging Spectroradiometer), Landsat, SPOT 5 and Sentinel 2-with appropriate field verification; with the exception of SPOT 5, generally every pass is collected. Other states rely on semiautomated imagery analysis to detect land use changes from the original land use mapping (OEH, 2016b). Utilising research undertaken by the Joint Remote Sensing Research Program provides the opportunity to use Landsat- and SPOT 5-based multi-temporal information to detect the probability of land use change through woody change detection and seasonal fractional cover analysis.
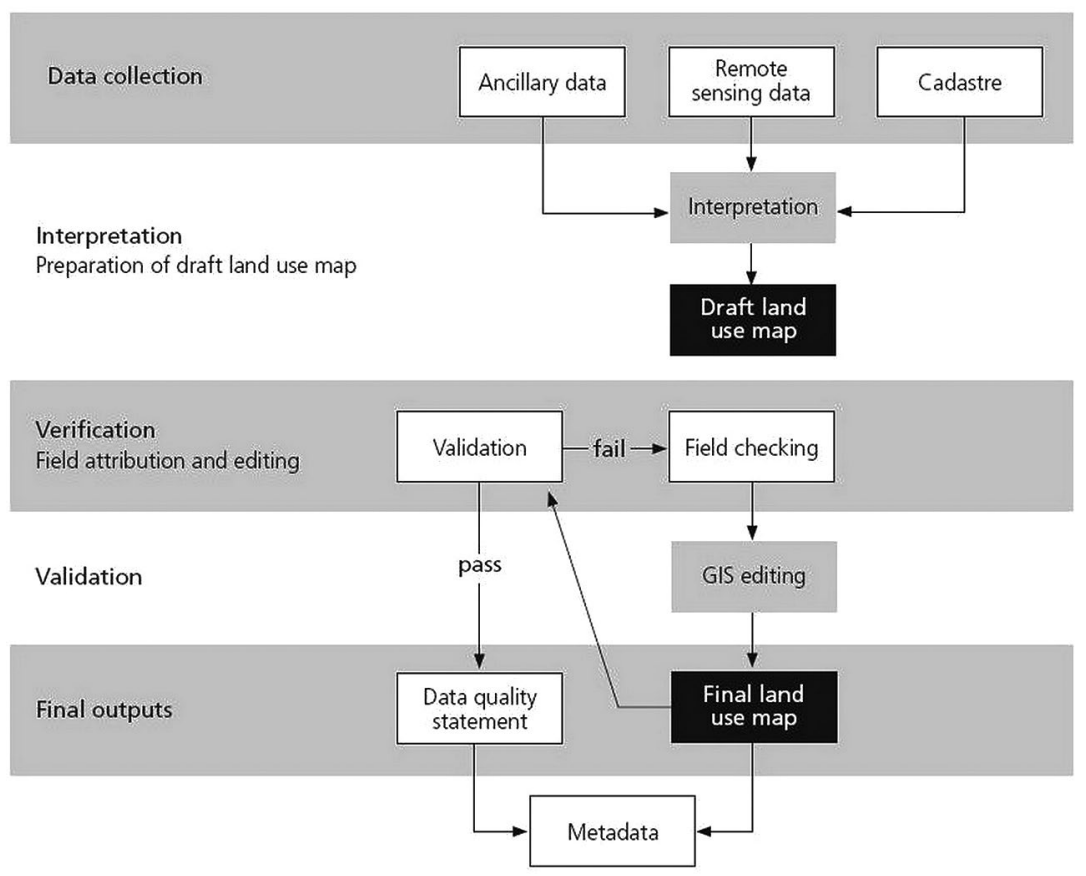

Figure 6.2: Land use mapping procedure.

Note: GIS = geographic information system.

Source: ABARES (2011, Figure 6).

Mapping techniques are rapidly adapting to new innovations, such as aerial and satellite imagery available through Web Map Services (WMS) and geographic information system (GIS) plugins. Examples include Planet Labs (satellite), Nearmap (aerial) and Google Earth (aerial and 
satellite). WMS provide imagery to consumers much more quickly than traditional imagery acquisition techniques. This expansion in data types and accessibility enables jurisdictions to more rapidly update their land use data holdings. To ensure consistency across jurisdictions in land use mapping products, an Australian land use classification and generic mapping procedure was developed (see Figure 6.2).

\section{Intrastate and Territory Benefits}

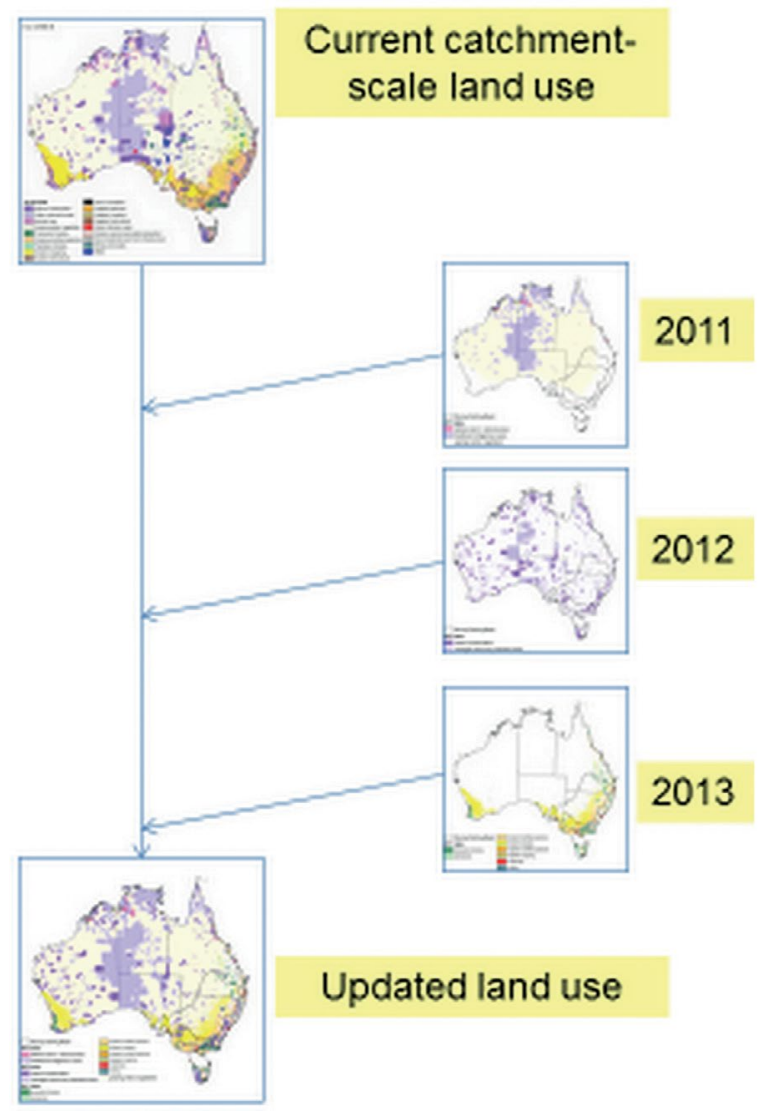

Figure 6.3: Updating land use mapping by incorporating changes detected by acquiring annual imagery.

Source: Randall, Mewett \& Purcell (2015, based on Figure 3).

Each state has different priorities and available resources to undertake land use mapping. The national ACLUMP standards provide the framework for the different state-based land use mapping programs. Using the 
ACLUMP framework for land use classification and mapping, the larger states can collect annual (or every pass of available) imagery. This access to regularly available new data is driving an 'updating by exception' approach to land use and land cover mapping (see Figure 6.3), whereby states update the underlying datasets by identifying areas of change using satellite and recent aerial imagery. This approach, which does away with the need for new mapping programs to update land use, is made possible with the help of modern, high-capacity remote-sensing computing systems. It assists with updating land use mapping in a resource-constrained environment by utilising authoritative ancillary datasets for specific land uses, and has enabled both larger and smaller states and territories to maintain their land use mapping programs (see ABARES, 2015).

\section{Interstate Benefits}

The adoption of a consistent system for classification and mapping provides an objective, robust and defensible framework for national and state land management initiatives. This has been brought about by:

- using a common set of terms and descriptions

- sharing common database attributes and algorithms, enabling increasing levels of interoperability, and efficiency gains in mapping approaches between state and national programs

- improved understandings of common techniques and landscape impacts associated with land management practice across multiple jurisdictions (e.g. cultivation practices such as minimum tillage and direct drilling)

- awareness that patterns in land cover can relate to management practice and land use.

\section{Land Use Case Studies}

The need for more comprehensive information on land use changes, especially in the larger states, is driven by issues associated with the protection of native vegetation and rapid urban expansion into surrounding agricultural areas. The following two examples, which highlight rapid change in land use over the past 10 years, show how land use and land management information has been deployed by government at local, regional and state levels. 


\section{Example 1: Moree Floodplains, NSW}

The primary driver for the Moree floodplains analysis was the NSW annual woody change detection program (part of the Statewide Landcover and Tree Study) that used annually acquired SPOT 5 satellite imagery. Cropping activity in the Moree floodplains, both dryland and irrigated, increased from 854,000 hectares in 2003 to 939,100 hectares in 2013nearly a 10 per cent increase in cropping activity over 10 years.

Figures $6.4 \mathrm{a}, 6.4 \mathrm{~b}$ and 6.5 show the expansion in cropping on the Moree floodplains over 10 years. The predominant land use change was the conversion of grazing lands, including areas that were covered by woody vegetation, into dryland and irrigated cropping. These insights were made possible by developing a time-series land use change dataset. Between 2004 and 2012, 6,485 hectares of woody vegetation change (loss) was attributed to agricultural activity for this study area. The extent of woody vegetation change detected for the study area is shown in Figures $6.4 \mathrm{a}$ and $6.4 \mathrm{~b}$.

For the areas identified as grazing intensification (Figure 6.5), 12,100 hectares were marked as grazing of native vegetation (land use c. 2003), whereby the woody component had been removed. It is likely that these areas are in a transitional phase, and that they will become areas of cropping activity in the future (see Table 6.1). These areas would be the focus for future land use updates. This type of information has informed policy directions being enacted by the NSW Government (e.g. recent biodiversity conservation legislation changes), especially with regard to the implementation of legislative controls over the loss of native vegetation and conversions of grazing land uses to cropping.

This study of changes in land use has been used to assess the impacts of cultivation expansion on natural resources: soil, water and extent of native vegetation. It has also been used to assess the impacts on biodiversity, groundwater and flood-dependent ecosystems in over-cleared landscapes, based on the NSW Mitchell Landscapes version 3 (OEH, 2011). In addition, it has been used in the NSW Healthy Floodplains ProjectFloodplain Management Plans (Department of Primary Industries, 2011) and state vegetation-type mapping and landscape modelling $(\mathrm{OEH}$, 2016a). It was a precursor scoping study for the NSW Biodiversity Act Map, as part of the NSW Biodiversity Legislation Review. 

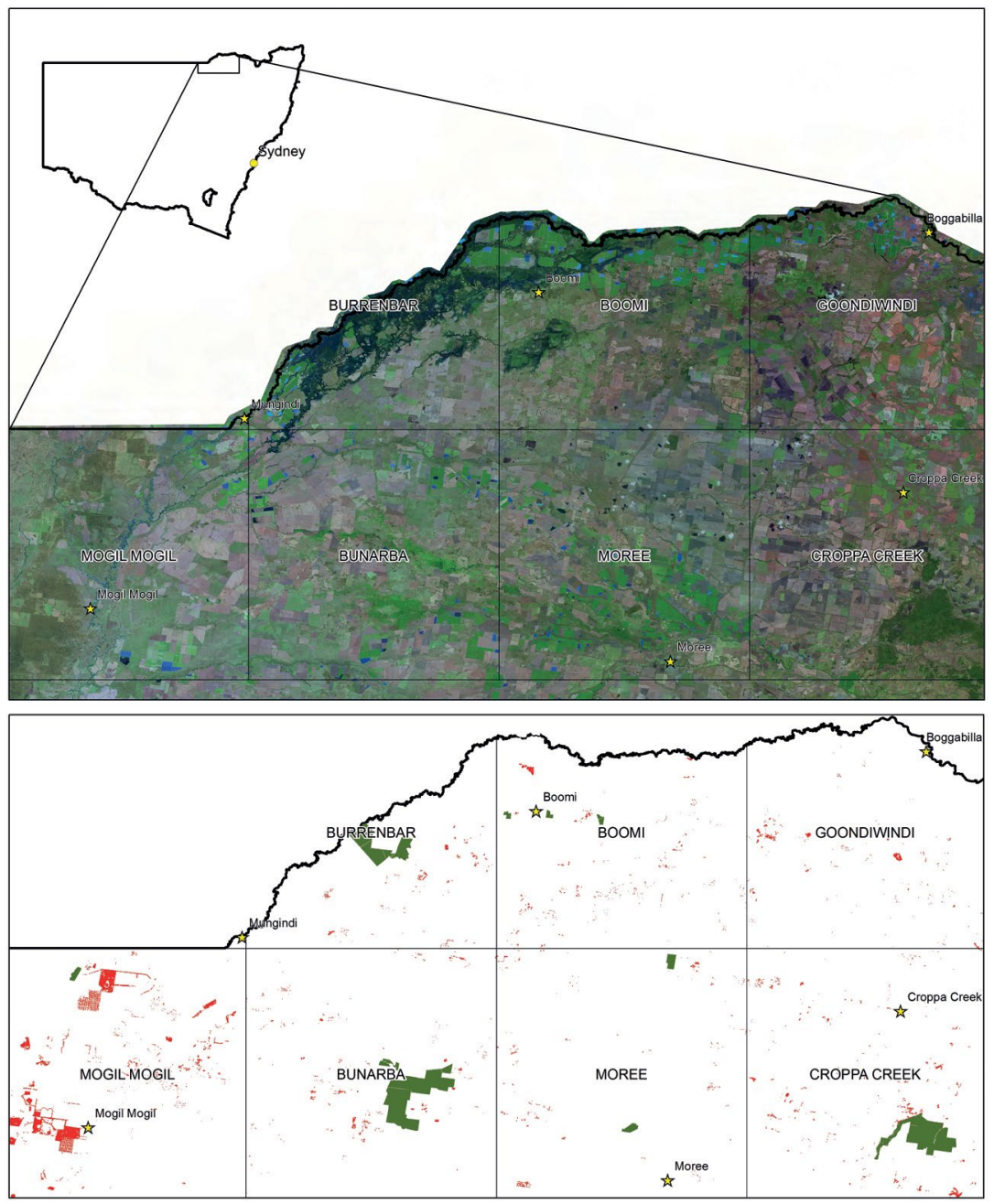

NSW SLATS Woody Change 2004 -2012

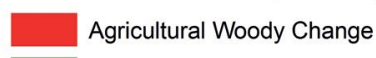

Reserve

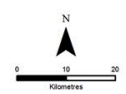

Figures 6.4a and 6.4b: Extent of land use changes on the Moree floodplains (1:100,000 topographic map sheets illustrated), showing the loss of woody vegetation, 2004-12, New South Wales Statewide Landcover and Tree Study Program.

Source: OEH (2016b), used with permission. 
LAND USE IN AUSTRALIA

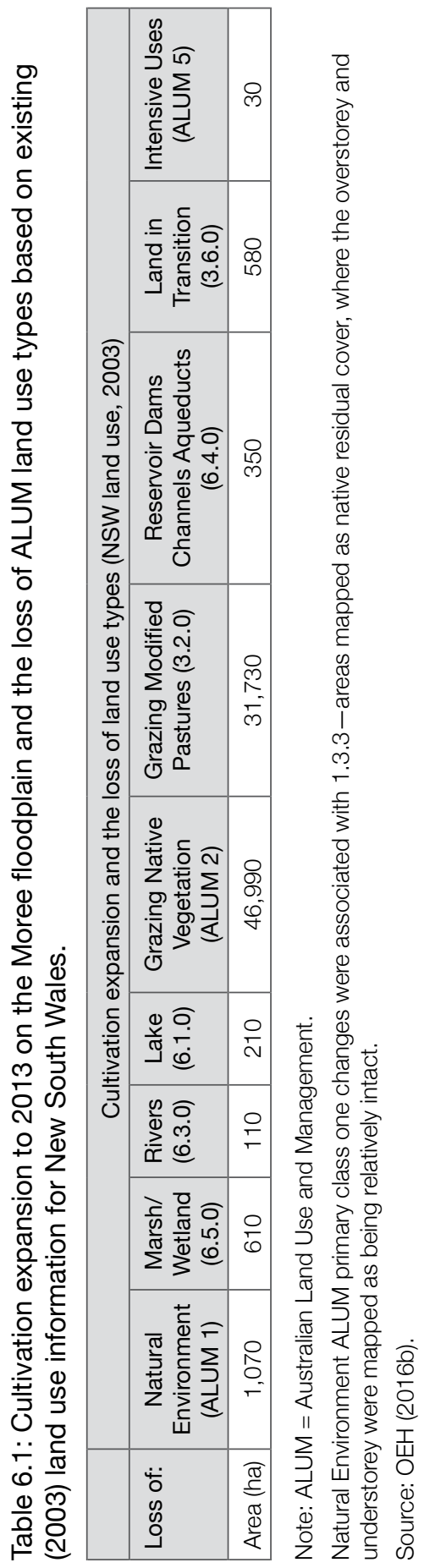



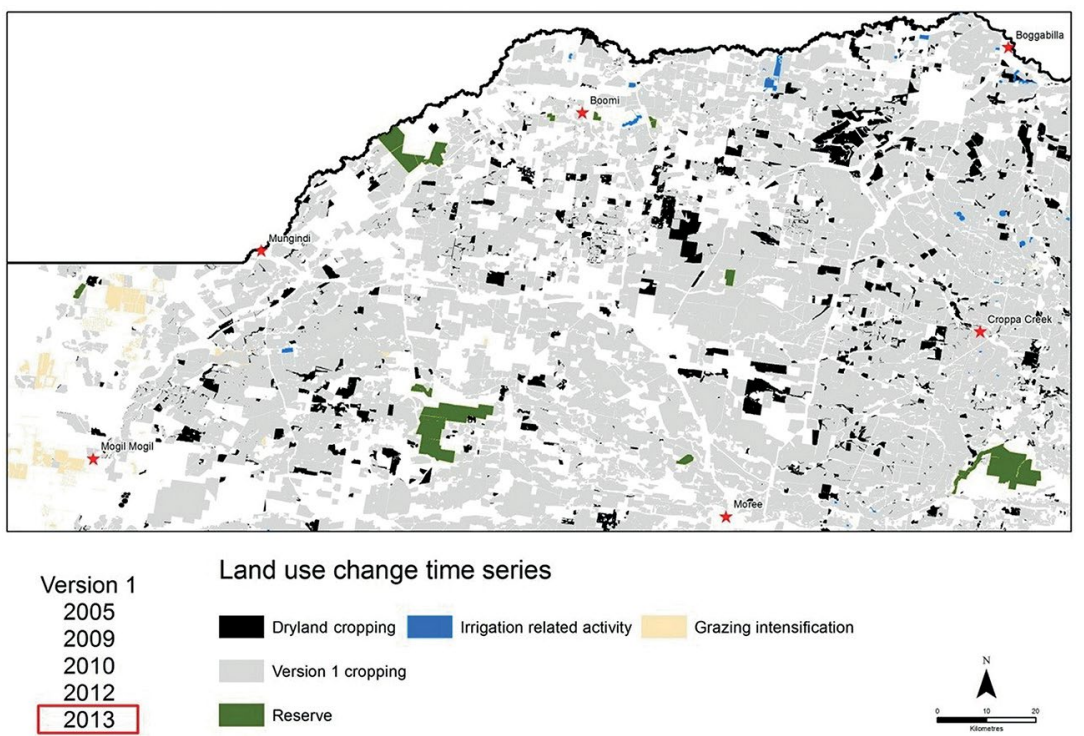

Figure 6.5: Extent of land use change on the Moree floodplains, 2003-13.

Note: The light grey shows the cropping extent in 2003. The expansion of dryland cropping is shown in black and irrigated cropping in blue.

Source: OEH (2016b).

\section{Example 2: Maitland Local Government Area}

Maitland has undergone a rapid increase in population in recent years; indeed, it has experienced the largest population growth among inland centres in NSW. A service centre for Newcastle and the Hunter Valley, and located within easy commuting distance of Newcastle and the Hunter Valley coalmines, its commercial areas have expanded to service the mining industry and to provide household retail outlets (see Figures 6.6, $6.7 \mathrm{a}$ and $6.7 \mathrm{~b})$.

Updated land use information for the Maitland local government area and Hunter Valley was provided to the NSW Departments of Planning and Environment (DPE) and Primary Industries for the Upper Hunter Strategic Regional Land Use Plan (UHSRLUP) (DPE, 2012) (see Table 6.2). The information was used to assist in identifying land use activities present in the Upper Hunter Valley, including the extent of mining operations and critical industries clusters (agriculture) defined in the UHSRLUP. Land use information is now critical for future regional planning in Australia and is actively considered in the planning processes used by state planning agencies. 


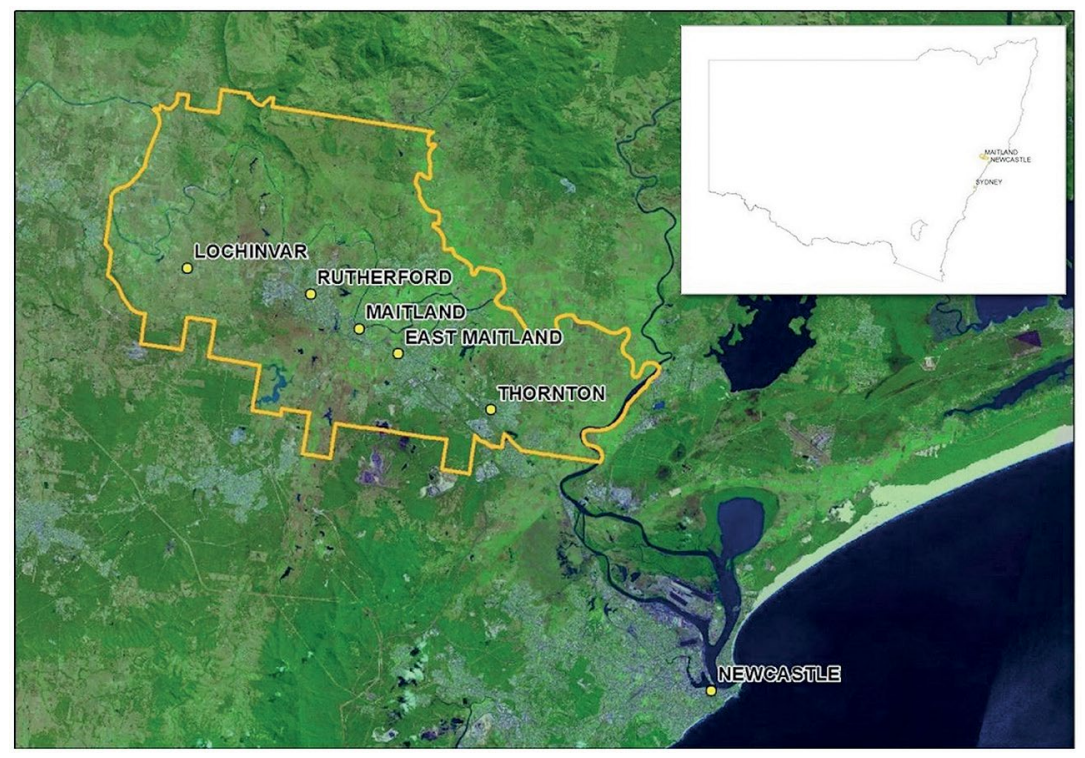

Figure 6.6: Maitland local government area.

Source: OEH (2016b).

Table 6.2: Changes in land use for Maitland local government area at the ALUM primary classification level, based on existing (2003) NSW land use information and mapped changes (2013).

\begin{tabular}{|l|r|r|r|}
\hline ALUM primary classes & $\begin{array}{c}2003 \\
(\%)\end{array}$ & $\begin{array}{c}2013 \\
(\%)\end{array}$ & $\begin{array}{c}\% \\
\text { Difference }\end{array}$ \\
\hline 1. Conservation and natural environments & 5.0 & 4.7 & -0.3 \\
\hline 2. Production from relatively natural environments & 0 & 0 & 0 \\
\hline 3. Production from dryland agriculture and plantations & 70.7 & 64.4 & -5.6 \\
\hline 4. Production from irrigated agriculture and plantations & 4.9 & 2.8 & -2.1 \\
\hline 5. Intensive uses & 13.5 & 21.5 & 8.1 \\
\hline 6. Water & 5.8 & 6.6 & 0.8 \\
\hline
\end{tabular}

Note: ALUM = Australian Land Use and Management

Loss of ALUM primary class 1 is attributed to the loss of forested areas 1.3.3-residual native cover (NSW land use, 2003).

Source: OEH (2011). 

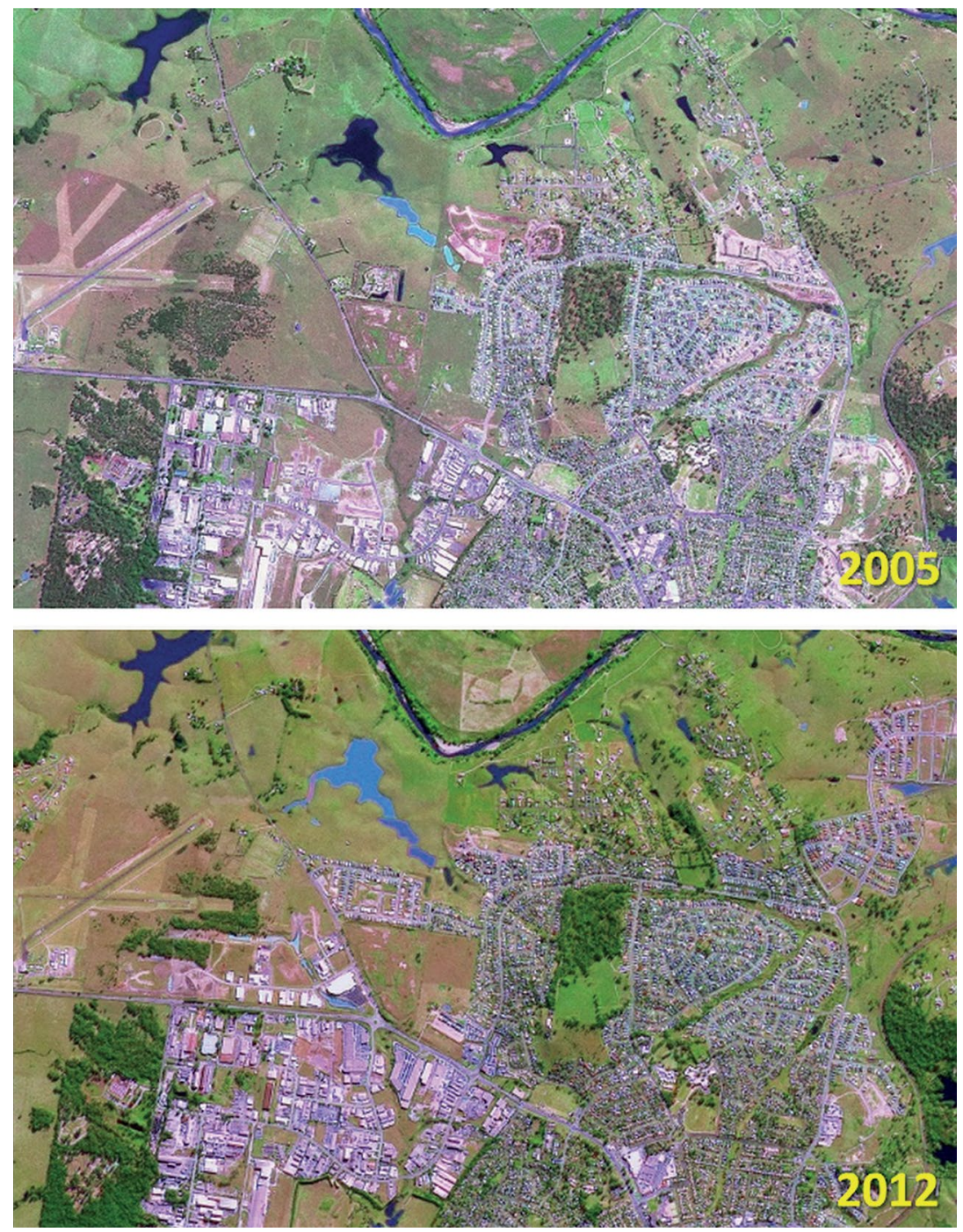

Figures 6.7a and 6.7b: Decline in dryland and irrigated agriculture and increase in intensive uses. Residential, commercial and light industrial expansion around Rutherford, north-western edge of Maitland developed area.

Source: OEH (2016b). 


\section{Conclusions}

The need for ongoing improvements to the datasets (and to abilities to correlate this information with other information) will only increase over time-for example, due to the growing demand for land use information to support biosecurity planning and emergency responses. In addition, the changes in land use associated with a changing climate are becoming apparent, with major shifts in cropping practices occurring in southern NSW and Victoria due to the decline in winter rainfall.

Australia's land stock, particularly in the southern half of the continent, is undergoing steady intensification of use as the population grows. This pressure requires an ongoing commitment by governments to provide quality information to support the required planning and development activities (Budge et al., 2012). In the northern half of Australia, considerable effort is being put into capability-suitability assessments to identify possible areas for intensification of agricultural output. Predictive modelling is now used as part of the planning process and it requires data on current land use and land management at scales appropriate to the problems being addressed. Owing to the open data policies now in place, maps of current land use and alternative land use scenarios also help communities to participate in proposed development planning.

Future advancements in land use mapping will come from improvements in satellite monitoring technology, such as improved resolution and repeat cycle times and improvements to automated mapping approaches (e.g. machine learning for change recognition and image segmentation technology enabling efficiencies, and improvements in the accuracy and objectivity of the state-based and national programs).

Land use mapping at catchment scale is now generally available in the more intensively used areas of Australia (i.e. non-arid zones) apart from Victoria, which is covered by 1:100,000-scale mapping. Nationally agreed methods, developed under ACLUMP, have provided for cost-effective production, making best use of pre-existing land use information contained in sources such as cadastre (i.e. property-boundary information), public land and valuation databases, and land cover mapping programs.

Coordinated land use information relevant for policy and planning is critical to support state and national issues, such as biosecurity, as it provides underpinning land use location data for specialised industry activities: 
for example, detailed mapping of the location of banana plantations across Queensland, NSW and Western Australia as part of the response to the Panama Tropical Race 4 disease outbreak. State agencies using ACLUMP to map those regions where there is a focus on horticultural commodities and intensive animal industries in collaboration with state biosecurity agencies and industry are another example.

Maintaining up-to-date and appropriately detailed information on changes in land use type and extent is an ongoing challenge for the states and ACLUMP. Such information is critical to informing debates around agriculture and food security, forestry, water, mining (including coal seam gas extraction), climate change mitigation and adaptation, population growth, urban expansion, biodiversity protection and landscape aesthetics. However, a better understanding of agricultural land use change is required for informed analysis of the future of agricultural production and land management in Australia.

\section{References}

ABARES (Australian Bureau of Agricultural and Resource Economics and Sciences). (2011). Guidelines for land use mapping in Australia: Principles, procedures and definitions (4th ed.). Canberra, ACT: Australian Bureau of Agricultural and Resource Economics and Sciences. Retrieved from www.agriculture.gov.au/abares/publications/ display? url=http://143.188.17.20/anrdl/DAFFService/display. php?fid=pe_abares $99001806 . x \mathrm{ml}$

ABARES. (2015). Addendum to the guidelines for land use mapping in Australia: Principles, procedures and definitions (4th ed.). Canberra, ACT: Australian Bureau of Agricultural and Resource Economics and Sciences. Retrieved from agriculture.gov.au/abares/publications/ display?url=http://143.188.17.20/anrdl/DAFFService/display. php?fid=pe_agluma9abll20150415_11a.xml

ABARES. (2016). The Australian land use and management classification version 8. Canberra, ACT: Australian Bureau of Agricultural and resource Economics and Sciences. Retrieved from data.daff.gov.au/ anrdl/metadata_files/pe_alumc9aal20161017.xml 
ACLUMP (Australian Collaborative Land Use and Management Program). (2010a). Land use and land management information for Australia: Workplan of the Australian Collaborative Land Use and Management Program. Canberra, ACT: Australian Bureau of Agricultural and Resource Economics and Sciences, Canberra. Retrieved from www.agriculture.gov.au/abares/publications/display? url=http://143.188.17.20/anrdl/DAFFService/display.php?fid=pe_ abares99001769.xml

ACLUMP. (2010b). Status of land management practices activities of the Australian Collaborative Land Use and Management Program. Canberra, ACT: Australian Bureau of Agricultural and Resource Economics and Sciences, Canberra. Retrieved from www.agriculture.gov.au/abares/ publications/display?url=http://143.188.17.20/anrdl/DAFFService/ display.php?fid=pe_abares $99001770 . x m l$

Budge, T., Butt, A., Chesterfield, M., Kennedy, M., Buxton, M. \& Tremain, D. (2012). Does Australia need a national policy to preserve agricultural land? Surrey Hills, NSW: Australian Farm Institute.

Department of Agriculture. (1985). Pastoral potential in the Kimberley region, Western Australia: 1:500,000 scale maps and notes (Compiled from Land Systems Land Research Reports Nos 4, 9 and 28). Perth, WA: Rangeland Management Branch.

Department of Conservation and Land Management. (1992). Land management proposals for the integrated treatment and prevention of land degradation—catchment map series. Sydney, NSW: National Soil Conservation Program and Department of Conservation and Land Management.

DPE (Department of Planning and Environment). (2012). Strategic regional land use plan: New England north-west. Retrieved from www. planning.nsw.gov.au/ /media/Files/DPE/Plans-and-policies/strategicregional-land-use-plan-new-england-north-west-2012-09.ashx

Department of Primary Industries. (2011). Healthy floodplains. Retrieved from www.water.nsw.gov.au/water-management/waterrecovery/sustaining-the-basin/healthy-floodplains

Department of Water Resources. (1989). Water Victoria: An environmental handbook. Melbourne, VIC: Victorian Government Printing Office. 
Lesslie, R. G., Barson, M. M. \& Randall, L. A. (2008). Land use mapping. In N. J. McKenzie, M. J. Grundy, R. Webster \& A. J. RingroseVoase (Eds.), Guidelines for surveying soil and land resources (2nd ed., pp. 141-55). Melbourne, VIC: CSIRO Publishing.

Lesslie, R. G., Mewett, J. \& Walcott, J. (2011). Landscape in transition: Tracking land use change. Science and Economic Insights, 2.2. Retrieved from data.daff.gov.au/anrdl/metadata_files/pe_litlud9abll0790111a.xml

Mewett, J., Paplinska, J., Kelley, G., Lesslie, R. G., Pritchard, P. \& Atyeo, C. (2013). Towards national reporting on agricultural land use change in Australia (Technical Report 13.06). Canberra, ACT: Australian Bureau of Agricultural and Resource Economics and Sciences. Retrieved from www.agriculture.gov.au/abares/publications/display? url=http://143.188.17.20/anrdl/DAFFService/display.php?fid=pb_ nrlucd9ablm08320131011_11a.xml

OEH (Office of Environment and Heritage). (2011). Floodplain policies and management. Retrieved from www.environment.nsw.gov.au/ floodplains/index.htm; www.environment.nsw.gov.au/resources/flood plains/130528Valleyplans.pdf

OEH. (2016a). State vegetation type map. Retrieved from www. environment.nsw.gov.au/vegetation/state-vegetation-type-map.htm

OEH. (2016b). NSW woody change reports. Retrieved from www. environment.nsw.gov.au/vegetation/reports.htm

OEH. (2016c). Biodiversity conservation legislation—independent panel review. Retrieved from www.environment.nsw.gov.au/biodiversity legislation/review.htm

OEH. (2016d). Biodiversity conservation legislation-native vegetation regulatory map development. Retrieved from www.landmanagement. nsw.gov.au

Randall, L., Mewett, J. \& Purcell, J. (2015). Murray-Darling Basin land use project (Report). Canberra, ACT: Department of Agriculture and Water Resources and Australian Bureau of Agricultural and Resource Economics and Sciences. Retrieved from data.daff.gov.au/anrdl/ metadata_files/pc_mdblud9aal20150618_11a.xml 
Thackway, R. \& Freudenberger, D. (2016). Accounting for the drivers that degrade and restore landscape functions in Australia [Special Issue]. Land 5(4), 1-20. doi.org/10.3390/land5040040

Weston E. J., Harbison, J. K., Leslie J., Rosenthal, K. M. \& Mayer, R. J. (1981). Assessment of the agricultural and pastoral potential of Queensland. Brisbane, QLD: Department of Primary Industries. 
This text is taken from Land Use in Australia: Past, Present and Future, edited by Richard Thackway, published 2018 by ANU eView, The Australian National University, Canberra, Australia.

doi.org/10.22459/LUA.02.2018.06 